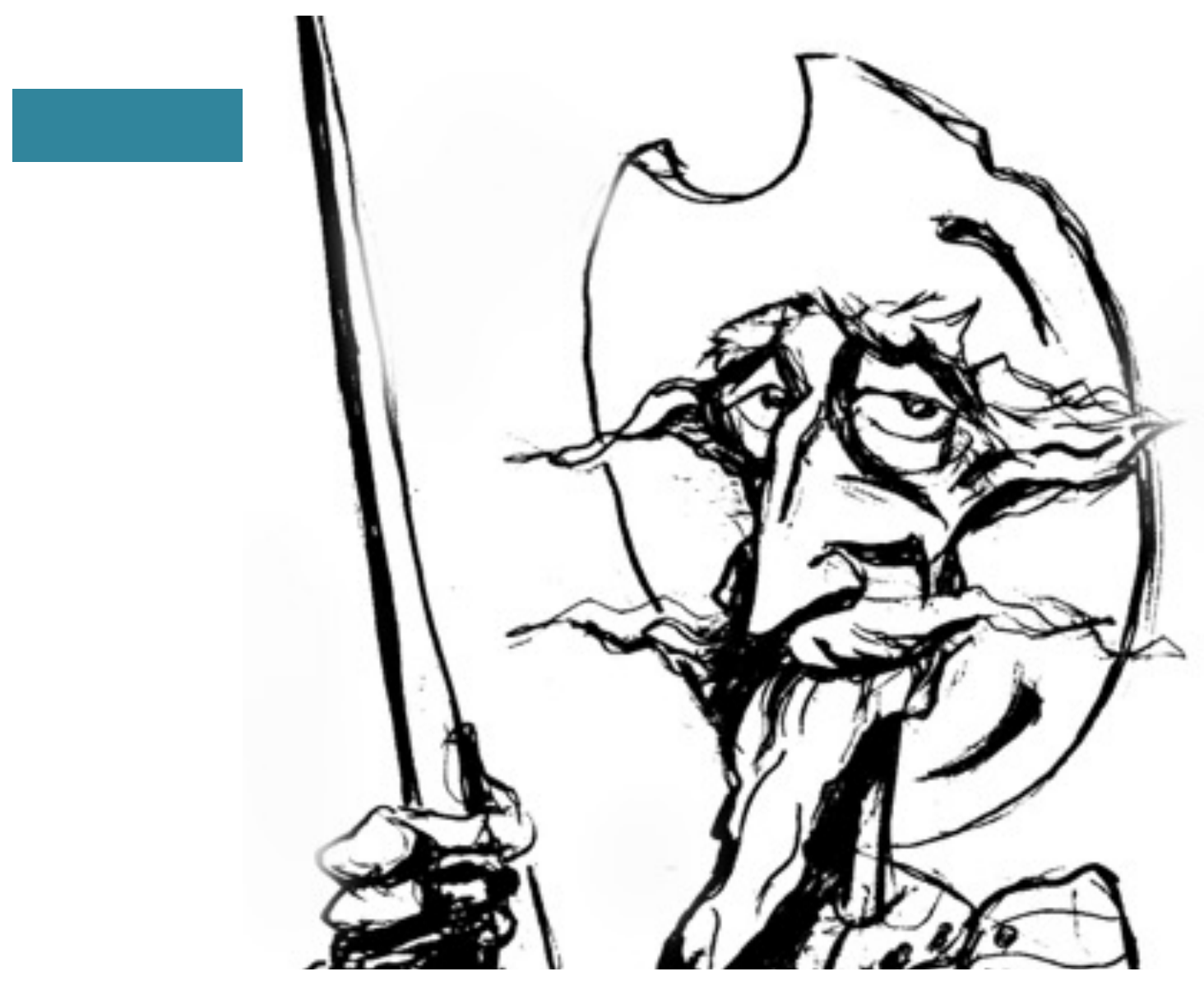

La educación media durante el primer peronismo.

Matices en torno a los conceptos de Democratización, Adoctrinamiento (1946-1952)

[Leonardo Mario Fonte] 


\title{
La educación media durante el primer peronismo. Matices en torno a los conceptos de Democratización, Adoctrinamiento (1946-1952)*
}

\author{
Middle Level Education during the First Peronism. \\ Nuances around the Concepts of Democratization, Indoctrination (1946-1952)
}

\section{LEONARDO MARIO FONTE}

\section{Resumen}

La llegada de Juan Domingo Perón, a la presidencia de la Nación, es visualizada como un punto de inflexión en el desarrollo de la estructuración del sistema educativo argentino. Consecuentemente, los análisis académicos que abordan esta temática, mayoritariamente centrados en el nivel primario, no logran alejarse del reduccionismo que implica caracterizar la política educativa peronista en términos de democratización y adoctrinamiento. En este sentido, la ausencia de trabajos que permitan matizar dichas conceptualizaciones analíticas dota al presente estudio de una gran responsabilidad: dar cuenta de los alcances del proceso de restructuración del nivel medio de la educación, para las escuelas de Capital Federal y de los territorios Nacionales, entre los años 1946 y 1952.

\section{Palabras Clave}

Peronismo - Educación - Democratización Adoctrinamiento - Ciclo Básico Bachiller

\begin{abstract}
The arrival of Juan Domingo Perón to the presidency of the nation is considered an inflexion point in the development of the Argentinian educational system organization. Consequently, the academic analyses which approach this subject, mainly focused on primary school, do not manage to move away from the reductionism which implies the characterization of the educational policy in terms of democratization and indoctrination. In this sense, the lack of papers that nuance this conceptual binomial, endows the present study with a great responsibility: to give an account of the results of the restructuration in middle level education, for the schools of the Federal Capital and of the National Territories, between 1946 and 1952.
\end{abstract}

\section{Key Words}

Peronism - Education - Democratization Indoctrination - High School

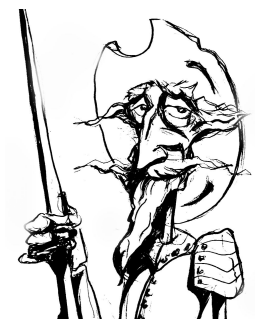

Recibido con pedido de publicación el 30 de abril de 2018

Aceptado para su publicación el 10 de julio de 2018

Versión definitiva recibida el 2 de octubre de 2018

Leonardo Mario Fonte, Universidad Nacional de Tres de Febrero, Argentina; e-mail: lfonte@untref.edu.ar

\footnotetext{
* Agradezco las sugerencias de las/os evaluadoras/es de Revista Prohistoria

Esta obra se publica bajo licencia Creative Commons. Atribución-NoComercial-CompartirIgual 4.0 Internacional
}

Fonte, Leonardo Mario “La educación media durante el primer peronismo. Matices en torno a los conceptos de Democratización, Adoctrinamiento (1946-1952)”, Prohistoria, Año XXI, núm. 30, dic. 2018, pp. 155-182. 
Prohistoria, Año XXI, núm. 30, dic. 2018, ISSN 1851-9504 


\section{Introducción}

La producción de estudios académicos que buscan analizar la impronta del primer peronismo, lejos de encontrarse agotada, ha derivado en una multiplicidad de análisis que evidencian la plena vigencia de este tema. ${ }^{1}$ En este sentido las investigaciones que caracterizan el derrotero de las reformas acontecidas en el ámbito educativo, durante el período en cuestión, no se han mantenido exentas de este fenómeno y han continuado experimentando una gran proliferación. ${ }^{2}$ La educación en el peronismo ha acabado por constituirse en un paradigma analítico abordado desde las más variadas perspectivas, en búsqueda de respuestas para un sinfín de interrogantes. ${ }^{3}$

La divergencia analítica que caracteriza los estudios que reconstruyen el mundo educativo durante el primer peronismo, encuentra sus matices en algunos puntos en común que estructuran la mayor parte de estos trabajos. En

\footnotetext{
${ }^{1}$ Sobre balances bibliográficos referidos a diversas producciones relativas a estudios centrados en el primer peronismo, entre otros, ver: PULFER, Darío El peronismo en sus fuentes. Una guía bibliográfica para su estudio, Ediciones Ciccus, Buenos Aires, 2012; REIN, Raanan, BARRY, Carolina, QUIROGA, Nicolás y ACHA, Omar Los estudios sobre el primer peronismo. Aproximaciones desde el siglo XXI, Instituto Cultural de la provincia de Buenos Aires, La Plata, 2009.

2 Para balances sobre trabajos que analizan al sistema educativo peronista, entre otros, ver: PERRUPATO, Sebastián "Historiografía y educación peronista: Un estado de la cuestión sobre la historia de la educación durante el primer peronismo", en Historia y Espacio, núm. 40, 2013, pp. 149-165. PETITTI, Eva Mara "Notas en torno a los estudios sobre educación durante el peronismo", en A Contra Corriente, vol. 9, núm. 3, 2012, pp. 199-224.

${ }^{3}$ Para estudios vinculados al análisis de los cambios operados en los libros de texto y los Planes y Programas de Estudios, ver: CORBIERE, Emilio Mamá me mima, evita me ama: la educación argentina en la encrucijada, Sudamericana, Barcelona, 1999; WAINERMAN, Catalina y HEREDIA, Mariana ¿Mamá amasa la masa? Cien años en los libros de la escuela primaria, Editorial Belgrano, Buenos Aires, 1999; SOMOZA RODRÍGUEZ, Miguel Educación y política en Argentina 1946-1955, Miño y Dávila, Buenos Aires, 2006. Para trabajos que caracterizan las prácticas escolares en clave de las dinámicas propias de sus instituciones, de la acción docente o desde la percepción de las revistas educativas, entre otros, ver: GVIRTS, Silvina "La politización de los contenidos escolares y la respuesta de los docentes primarios en los primeros gobiernos de Perón. Argentina 1949-1955", en Estudios Interdisciplinarios de América Latina y el Caribe, vol. 10, núm. 1, 1999, pp.112-140; COLOTTA, Pablo, CUCUZZA, Rubén y SOMOZA RODRÍGUEZ, Miguel “Textos y lecturas escolares durante el primer peronismo: Evita también fue palabra generadora", en CUCUZZA Rubén y PINEAU Pablo Para una historia de la enseñanza de la lectura y la escritura en Argentina: del catecismo colonial a La Razón de mi Vida, Miño y Dávila, Madrid, 2002; FINOCCIO, Silvia La escuela en la historia argentina, Edhasa, Buenos Aires, 2009. Para análisis que hacen foco en escalas regionales, provinciales o locales, ver: PINEAU, Pablo La validación de los campos de constitución de los sujetos: Discurso escolar y docentes en la provincia de Buenos Aires (1930-1955), Mimeo, Buenos Aires, 1998; PUIGGRÓS, Adriana y OSSANA, Edgardo La educación en las provincias (1945-1985), Galerna, Buenos Aires, 1997; PETITTI, Eva Mara "Política y educación en la Provincia de Buenos Aires durante el primer peronismo: reestructuración institucional e incorporación de nuevos actores (1946-1952)", en Espacios en Blanco, núm. 23, 2013, pp. 241-273.
} 
primera instancia, la mayoría de los análisis en relación a esta temática, identifican al gobierno peronista como una etapa de discontinuidad en el desarrollo de las prácticas educativas vigentes hasta ese momento. De tal forma, esta corriente analítica redundó en la reafirmación de un binomio conceptual que acabó por circunscribir los estudios sobre educación, para este período, a los tópicos de democratización y adoctrinamiento. ${ }^{4}$ Por otro lado se observa que las investigaciones referidas a la cuestión escolar durante el primer peronismo, se centran en el nivel primario de la educación, dejando de esta forma un marcado vacío historiográfico en lo que refiere al estudio de la configuración de la educación secundaria. ${ }^{5}$ En el mismo sentido, se debe señalar que los escasos trabajos que se hacen foco específicamente en esta instancia formativa se caracterizan, tal como se enunció con anterioridad, por mantener una dependencia para con aquellos conceptos totalizadores que estructuran la mayor parte de la producción académica basada en la historia de la educación durante el peronismo.

El trabajo de Claudio Panella, titulado "Una aproximación a la enseñanza secundaria durante los primeros gobiernos peronistas (1946-1955)", se evidencia como el primer análisis centrado en el estudio del segundo tramo formativo del sistema educativo argentino, durante los dos primeros mandatos justicialistas. ${ }^{6}$ Desde este artículo, centrándose en el concepto de democratización, el autor se propone demostrar que el progreso experimentado por amplios sectores de la sociedad argentina, en los años del primer peronismo, tuvo uno de sus ejemplos más notorios en el área educativa. Esta afirmación, a su entender, se sustenta en el claro éxito alcanzado por el General Perón al momento de procurar la

\footnotetext{
${ }^{4}$ La visión respecto a que el peronismo inició una nueva etapa en el desarrollo del sistema educativo nacional, gira principalmente en torno a dos perspectivas. Por un lado, se encuentran aquellos trabajos que dan cuenta de una ampliación de derechos dirigida a sectores hasta el momento postergados, entre los que se destacan: BERNETTI, Jorge y PUIGGRÓS, Adriana Peronismo: Cultura política y educación (1945-1955), Editorial Galerna, Buenos Aires, 1993; TORRE, Juan Carlos y PASTORIZA, Elisa "La democratización del bienestar", en TORRE, Juan Carlos Los años peronistas (1943-1955), Sudamericana, Buenos Aires, 2002. Por otro lado, figuran aquellos análisis en los que se destaca la consolidación de un sistema de adoctrinamiento político hasta el momento inédito. Para el caso, entre otros, ver: PLOTKIN, Mariano Mañana es San Perón: propaganda, rituales políticos y educación en el régimen peronista 1945-1955, Ariel, Buenos Aires, 1994. REIN, Mónica y REIN, Raanan "Populismo y educación: el caso peronista", en Revista del Instituto de Investigaciones en Ciencias de la Educación, año V, núm. 8, 1996, pp. 50-57.

${ }^{5} \mathrm{El}$ caso de la educación técnica, se destaca como una excepción frente a la carestía de trabajos que versan sobre la educación secundaria. Sobre el tema, entre otros, ver: WIÑAR, David Poder político y educación. El peronismo y la Comisión Nacional de Aprendizaje y Orientación Profesional, Instituto Torcuato Di Tella, Buenos Aires, 1970; PINEAU, Pablo Sindicatos, estado y educación técnica 1936-1968, Centro Editor de América Latina, Buenos Aires, 1991.

6 PANELLA, Claudio "Una aproximación a la enseñanza secundaria durante los primeros gobiernos peronistas (1946-1955)", en Anuario del instituto de Historia Argentina, núm. 3, 2003, pp.139-157.
} 
cobertura de los servicios educativos para aquellos sectores de la población con menores ingresos. Es entonces dicho aumento matricular el que lleva al autor a analizar, de manera sintética, el lugar que ocupó el Estado en el desarrollo del quehacer educativo del nivel en cuestión.

Desde una propuesta analítica más integral que la esbozada por Claudio Panella, en su libro Educación y Política en Argentina, Miguel Somoza Rodríguez sostiene que la gestión educativa del peronismo combinó aspectos democratizadores con rasgos autoritarios. Frente a ello, identifica que la combinación particular de autoritarismo político y democracia social, acabó por dotar al gobierno peronista de una propia identidad "como movimiento y régimen político, sin que sea por ello ni excepcional, ni exclusivo, ni inaudito". ${ }^{7}$ En este sentido, y buscando distanciarse de los postulados de Mariano Plotkin, el autor se propone hacer extensiva su hipótesis al análisis de las reformas acontecidas en el nivel secundario. Empero el problema de su enfoque analítico reside en que, en su búsqueda por demostrar que la formación educativa peronista se caracterizó por combinar elementos tradicionales con prácticas innovadoras, su mirada se acaba encorsetando en el terreno argumentativo del autor de Mañana es San Perón. Es así que en el capítulo que dedica a indagar el desarrollo de las prácticas educativas, que caracterizaron al nivel secundario, se limita a analizar exclusivamente la reforma curricular que, entre 1952 y 1955, dio origen a la materia Cultura Ciudadana. ${ }^{8}$ De esta forma, margina de su análisis tanto el derrotero de reformas educativas previas a la aplicación del Segundo Plan Quinquenal, como la impronta de las transformaciones educativas de la segunda presidencia de Juan Domingo Perón por fuera de la materia considerada como el emblema de la peronización de los contenidos.

Finalmente, en una serie de trabajos que confluyeron en la publicación del libro Somos Bachiyeres, Adrián Cammarota vincula dialécticamente los conceptos de democratización y adoctrinamiento, en el desarrollo de las prácticas educativas del nivel secundario, a la luz de lo acontecido en colegio mixto Nacional de Morón, desde su fundación en el año 1949. ${ }^{9}$ Para el caso el autor identifica que, a causa de la saturación que produjo la incorporación de miles de jóvenes al sistema educativo, durante la segunda presidencia

\footnotetext{
7 SOMOZA RODRÍGUEZ, Miguel Educación..., cit., p. 310.

${ }^{8}$ SOMOZA RODRÍGUEZ, Miguel Educación..., cit., pp. 227-278.

${ }_{9}$ CAMMAROTA, Adrián Somos Bachiyeres, Biblos, Buenos Aires, 2014. Este libro se constituye en la culminación de un recorrido analítico plasmado en una serie de publicaciones del mismo autor, entre las que se destacan: "El Ministerio de Educación durante el peronismo: ideología, centralización, burocratización y racionalización administrativa (1949-1955)", en Revista historia de la Educación Latinoamericana, vol. 15, 2010, pp. 63-92 y “Consideraciones sobre la educación media humanística bajo el primer peronismo (1946-1955): expansión de la matrícula secundaria, inversión estatal y orden educativo meritorio", en Temas de historia argentina y americana, núm. 19, 2011, pp. 46-93.
} 
peronista, la distribución material fue reemplazada por una suerte de distribución simbólica sustentada en la formación de una imaginario social que santificó la imagen de Eva Perón, sacralizó la simbología peronista y resignificó la historia argentina. ${ }^{10}$

La recurrencia analítica que presentan los trabajos hasta aquí enunciados, amerita el desarrollo de un estudio, que profundice en el proceso de restructuración llevado a cabo por el gobierno peronista, en el nivel medio de la educación, desde el que se pueda matizar el binomio conceptual democratización y adoctrinamiento. Es por ello que, en pos de este objetivo, desde el presente trabajo se analizan las reformas aplicadas en el Ciclo Básico Bachiller de los colegios secundarios de Capital Federal y de los territorios Nacionales, entre los años 1946 y 1952. La delimitación del recorte temporal radica en la intención de eludir la concreción de un análisis que se centre en la cuestión de la peronización de los contenidos escolares, permitiendo de esta forma identificar la impronta de las acciones pedagógicas previas a la ejecución del Segundo Plan Quinquenal. Por otro lado, se debe enunciar que la elección del Ciclo Básico Bachiller como unidad de análisis responde al reconocimiento que el mismo gobierno peronista le otorgó a esta instancia formativa, correspondiente a los tres primeros años de las escuelas Normales y de los colegios Nacionales.

Al momento de estructurar el desarrollo analítico del presente trabajo, se aborda el tema desde dos perspectivas. En primer lugar, frente a los niveles de desgranamiento matricular evidenciados en las distintas cohortes que iniciaron sus estudios durante este período, se busca matizar la idea de que el éxito de una política de inclusión pueda ser medido solo consignando la cantidad de alumnos inscriptos anualmente. Al respecto, se interpreta como fundamental contemplar cuántos de esos nuevos ingresantes que comenzaron a cursar primer año, alcanzaron a proseguir sus estudios más allá del Ciclo Básico Bachiller. En tal sentido se identifica que el reconocimiento oficial de la terminalidad de este tramo formativo, que pasó a incluir el otorgamiento de un título de nivel nacional, se constituyó en una estrategia del gobierno en la búsqueda por aumentar su injerencia en el control matricular de esta instancia educativa.

En segundo término se estudia el proceso mediante el cual, durante la primera presidencia peronista, se buscó modificar los contenidos y las prácticas pedagógicas propias del Ciclo Básico Bachiller. En un contexto en el que la matrícula de las distintas cohortes se desgranaba acorde los estudiantes avanzaban en sus trayectos formativos, resultaba fundamental restructurar las prácticas escolares del nivel en cuestión. De esta forma el gobierno podría

${ }^{10}$ CAMMAROTA, Adrián “El Ministerio...”, cit., p. 79. 
garantizar que, durante el tiempo en que estos jóvenes permanecieran bajo el influjo del sistema educativo formal, se constituirían en sujetos útiles para la Nación. Por otro lado, el estudio del derrotero del accionar reformista llevado a cabo por el peronismo permite analizar la política educativa peronista por fuera de la idea de adoctrinamiento. Paralelamente, a través del análisis de distintos canales de participación con los que el gobierno instó a la colaboración de los docentes en este proceso de reformas, se busca matizar las ideas que refieren que, a lo largo de este período, los educadores acabaron siendo interpelados, por el gobierno, como ejecutores pasivos de las políticas educativas peronistas. ${ }^{11}$

Por último, cabe destacar que el trabajo minucioso sobre las reformas de los Planes y Programas de Estudio, las normativas de índole educativa, y las documentaciones que se encuentran disponibles en los archivos históricos de diversos establecimientos de educación media, dan cuenta de una serie de elementos que contribuyen a la comprensión de la temática en cuestión. ${ }^{12}$

\section{El Ciclo Básico Bachiller y la cuestión matricular}

El proceso que concluyó con el reconocimiento oficial del Ciclo Básico Bachiller, como una instancia formativa con terminalidad propia, evidenció la intención del gobierno peronista por aumentar su control sobre la evolución matricular del nivel medio de la educación. En un contexto caracterizado por un alto índice de desgranamiento de la matrícula, en los primeros años de la escuela secundaria, esta medida primeramente tuvo como objeto incrementar la cantidad de jóvenes que pudieran culminar la cursada del Ciclo Básico Común. Pero, frente a la necesidad de regular la "producción" de docentes habilitados para dar clases en las escuelas primarias, el reconocimiento del derecho a la obtención de un título Bachiller Elemental también le permitió al Estado redireccionar el trayecto formativo de aquellos jóvenes que, por no ser considerados aptos para el ejercicio de la docencia, hubieran sido marginados del Ciclo Superior de las escuelas Normales.

\footnotetext{
${ }^{11}$ Desde esta perspectiva, Silvina Gvirtz da cuenta de las prácticas sistemáticas de confrontación de los docentes del nivel primario frente a la introducción curricular de contenidos partidarios. GVIRTS, Silvina "La politización...", cit.

${ }^{12} \mathrm{El}$ acervo documental que estructura parte del presente trabajo fue obtenido de los archivos escolares de instituciones secundarias que forman parte del proyecto Huellas en la Escuela. Esta iniciativa, impulsada por el gobierno de la Ciudad de Buenos Aires, consiste en la recuperación del patrimonio histórico existente en distintos establecimientos educativos. Entre las instituciones consultadas se destacan: el Colegio núm. 1 Domingo Faustino Sarmiento, la Escuela Normal núm. 1 Presidente Roque Sáenz Peña y el Colegio Nacional núm. 2 Mariano Acosta.
} 


\section{El Ciclo Básico Bachiller como etapa formativa con terminalidad propia}

A partir del año 1941, con la aprobación del Decreto No 101.107, se estableció un ordenamiento de las asignaturas de los Planes de estudios del Bachillerato y el Magisterio con el objeto de poder estructurar estas instancias formativas en dos tramos. ${ }^{13}$ La normativa en cuestión pasó a incluir un primer Ciclo Común para ambas ramas de la enseñanza media, y posteriormente un segundo nivel que se encontró diferenciado de acuerdo con la finalidad propia de cada una de estas instancias. Desde entonces, se unificó la preparación básica de los futuros bachilleres y maestros, con el fin de evitar que los estudiantes se vieran obligados a definir prematuramente su orientación hacia unos $u$ otros

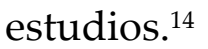

En el año 1947, en el marco de la puesta en marcha del Primer Plan Quinquenal, el gobierno peronista revalidó la vigencia de la estructuración en dos tramos de la educación media y reivindicó sus principios. Mediante la aprobación del Decreto No 26.944, se enunciaba que el correcto ordenamiento de las instancias formativas de la segunda enseñanza contribuía a delimitar el objetivo de un tipo de educación que debía ser funcional para la formación de la conciencia nacional de sus alumnos. En tal sentido, según lo expresaba la normativa, la consolidación de un Ciclo Básico que fuera fundamentalmente formativo y humanista permitiría que los jóvenes pudieran desarrollar sus inquietudes, definir su vocación y comprender cuál era su papel en el proceso que conduciría al país a sus más altos destinos. ${ }^{15}$

Sumado a la intención de continuar con los principios de estructuración que habían caracterizado la educación media desde los últimos años, el gobierno también buscó adaptar la impronta de esta instancia formativa a la realidad socioeconómica del país. No era posible desconocer que uno de los principales motivos que determinaban el descenso matricular en el paso entre la escuela primaria y la educación media, residía principalmente en la imposibilidad de los jóvenes y sus familias de afrontar los gastos que implicaba la cursada del segundo ciclo de la enseñanza. ${ }^{16}$ Para el caso, dentro de los costos que acarreaba la cursada del nivel secundario, se incluía el pago obligatorio de matrículas anuales y de derechos de exámenes de fin de curso aplicados sobre todas las asignaturas. Estas evaluaciones finales, debían ser realizadas por todos los estudiantes, independientemente de la nota promedio anual obtenida por el

\footnotetext{
${ }^{13}$ Decreto núm. 101.107, 22 de septiembre de 1941.

${ }^{14}$ Esta medida fue complementada con la igualación de los requerimientos de ingreso para estos establecimientos de enseñanza. Ministerio de Justicia e Instrucción Pública, "Circular No 3", 14 de enero de 1942, Archivo Histórico del Colegio Nacional Roque Sáenz Peña (en adelante ARSP).

${ }^{15}$ Decreto núm. 26.944, 4 de septiembre de 1947.

${ }^{16}$ Decreto núm. 77.899, 4 de febrero de 1936.
} 
alumno, en pos de poder aprobar definitivamente cada una de las materias. ${ }^{17}$ Es por ello que, frente a esta situación, se estableció un sistema de becas que beneficiaría a aquellos padres que acreditaran carecer de los medios necesarios para costearla. Desde entonces, pasaron a ser beneficiarios del sistema de becas: las familias con tres o más hijos, los grupos familiares con ingresos insuficientes y los alumnos que se encontraran bajo tutela de asilos u otras instituciones de protección de menores, ya fueran públicas o privadas. ${ }^{18}$

La exención del pago de aranceles correspondientes a la cursada del nivel secundario, a pesar de constituirse en una medida emblema en búsqueda de la democratización del acceso a la enseñanza, no resultaba suficiente para garantizar que las familias con mayores dificultades económicas pudieran enviar a sus hijos a este nivel de estudio. ${ }^{19}$ En un mercado laboral en el que la población económicamente activa comprendía un grupo etario que iniciaba a los catorce años de edad, el hecho de que un joven cursara el segundo ciclo de la enseñanza a partir de sus doce años, implicaba que en muchos casos durante un mismo período se entrecruzaran las responsabilidades escolares con las necesidades laborales. ${ }^{20}$

En este contexto, en el que se evidenciaba una clara dificultad por garantizar la permanencia de los estudiantes en el nivel medio, el gobierno peronista acabó por reconocer el derecho de aquellos estudiantes que llegaran a culminar sus estudios correspondientes al Ciclo Común a obtener un título de Bachiller Elemental con carácter nacional. De esta forma la nueva normativa buscaba incentivar a los jóvenes a extender por tres años su trayecto formativo, en la escuela secundaria, en busca de un certificado de valor oficial que facilitara su acceso al mundo laboral o bien a institutos de capacitación de índole comercial, industrial o militar. ${ }^{21}$

\section{Los matices de la democratización del acceso a la educación media}

A pesar de la divergencia analítica que caracteriza los trabajos que buscan reconstruir el mundo educativo durante el primer peronismo, existe un consenso generalizado respecto al reconocimiento del aumento matricular

\footnotetext{
${ }_{17}$ Al respecto se debe destacar que, desde el año 1936, el "Reglamento de Clasificaciones, Exámenes y Promociones" exentó del pago de estos aranceles a aquellos estudiantes cuya calificación anual fuera mayor a ocho.

${ }^{18}$ Decreto núm. 9810, 15 de abril de 1947.

${ }^{19}$ La suspensión total de los aranceles que gravaban la enseñanza secundaria recién sería establecida, mediante el Decreto núm. 4495, 4 de abril de 1952.

${ }^{20}$ Dirección General del Servicio Estadístico Nacional, "Anuario Estadístico de la República Argentina" (1948), 55, Centro de Documentación de la Biblioteca Nacional del Maestro (en adelante BNM).

${ }^{21}$ Decreto núm. 29.289, 22 de septiembre de 1947.
} 
experimentado durante los años de su gestión. ${ }^{22}$ En efecto, tal como lo identifica Mara Petitti, la hipótesis de la democratización del acceso a la educación ha sido aceptada incluso por aquellos autores que centran sus estudios en los aspectos doctrinarios. $^{23}$ En el marco de la aceptación general del principio democratizador que caracterizó la política escolar peronista, resulta necesario identificar el problema metodológico que subyace en estos análisis vinculado a cómo se miden los alcances reales de dicha expansión.

Frente a la problemática enunciada, Adrián Cammarota indaga respecto a la dificultad que implica cuantificar los alcances de la política de inclusión educativa peronista para el caso del nivel secundario. Al respecto, este autor afirma que no basta con esbozar conclusiones que sentencien tajantemente que durante el período en cuestión se produjo una gran expansión de la matrícula de este nivel, basándose solo en la cantidad de alumnos matriculados anualmente. Por lo contrario, considera fundamental que los análisis que versen sobre este tema deben hacer foco en la triada "inclusión, permanencia y término". Es por ello que, dado que entiende que no existen datos fidedignos sobre el grado de deserción matricular experimentado en este tramo formativo, propone centrar la mirada en la comparación entre la cantidad de establecimientos educativos existentes desde las décadas anteriores a la etapa peronista y las instituciones educativas fundadas durante los años 1946 y 1955. El índice de aumento en las construcciones de nuevos establecimientos permitiría entonces, a su entender, evidenciar los alcances reales de la política de inclusión llevada a cabo por el peronismo. ${ }^{24}$

Si bien Cammarota afirma que no se poseen datos comprobables que permitan identificar el nivel de desgranamiento matricular de la educación media, el seguimiento individualizado de la evolución de las matriculas de cada una de las cohortes que cursaron sus estudios durante el período en cuestión, evidencia con claridad cuál fue el nivel de deserción que experimentó cada una de ellas. De esta forma resulta necesario visualizar cuántos de los ingresantes de primer año pudieron continuar con sus estudios, y cuántos de ellos acabaron por abandonarlos.

Los datos estadísticos requeridos para poder realizar un monitoreo matricular, como el que se propone, se encuentran en una fuente de utilización recurrente en los trabajos que abordan el desarrollo de la educación secundaria, durante el peronismo, desde una perspectiva cuantitativa: el Informe de

\footnotetext{
${ }^{22}$ Para el caso, entre otros, ver: BERNETTI, Jorge y PUIGGRÓS, Adriana Peronismo: Cultura..., cit.; TORRE Juan Carlos y PASTORIZA, Elisa "La democratización...", cit.; PANELLA, Claudio “Una aproximación...", cit.; SOMOZA RODRÍGUEZ, Miguel Educación y política..., cit.

${ }^{23}$ PETITTI, Mara Eva "Notas en torno...", cit., p. 211.

${ }^{24}$ CAMMAROTA, Adrián "Consideraciones sobre...", cit., p. 59.
} 
Enseñanza Media, 1914-1963..$^{25}$ Esta publicación realizada en el año 1963, por el Departamento de Estadísticas Educativas, presenta información que permite echar luz sobre cuestiones referidas al segundo tramo formativo de la educación secundaria argentina, en todas sus modalidades y niveles de dependencia, frente al vacío documental producido luego de que en 1948 se interrumpiera la edición del Anuario Estadístico de la Nación. Es entonces, a partir de este acervo informativo, que se propone analizar el desenvolvimiento matricular de la educación secundaria, partiendo de la lectura de las series cronológicas de alumnos matriculados, por año de estudio, en las Escuelas Nacionales y los Colegios Normales. ${ }^{26} \mathrm{Al}$ respecto cabe destacar que, si bien en el cuadro informativo que contiene estos datos, no se distingue entre los alumnos inscriptos en las escuelas de gestión pública y privada, la información que se brinda en la "serie cronológica por dependencia de establecimientos, divisiones, alumnos y profesores" permite identificar que sobre la cantidad total de estudiantes inscriptos anualmente en los Bachilleratos y los colegios Normales, el 31,95\% de los primeros y el 39,75\% de los segundos se correspondían con la gestión privada. ${ }^{27}$

Los índices de desgranamiento experimentado por las cohortes que iniciaron sus estudios entre los años 1944 y 1952, en el transcurso del Ciclo Básico Bachiller y el primer año del Ciclo Superior, pueden ser observados a través del análisis del Cuadro 1. En tal sentido, tal como se enunció con anterioridad, si bien los datos estadísticos que se presentan no son inéditos, el cambio de perspectiva reside en la forma en la que se los analiza. Mientras que los estudios que versan sobre el tema hacen una lectura horizontal de la información, en la que se identifica la cantidad total de inscripciones anuales, se destaca la necesidad de realizar una lectura diagonal de los datos que permita verificar cuántos de los ingresantes de cada cohorte abandonaron sus estudios a lo largo de este trayecto formativo.

\footnotetext{
${ }^{25}$ Estos datos estadísticos son retomados, entre otros, por: WIÑAR, David Poder político y educación. El peronismo y la Comisión Nacional de Aprendizaje y Orientación Profesional, Instituto Torcuato Di Tella, Buenos Aires, 1970; TORRE, Juan Carlos y PASTORIZA, Elisa "La democratización...", cit.; PANELLA, Claudio "Una aproximación...", cit.; CAMMAROTA, Adrián "Consideraciones sobre...", cit.

${ }^{26}$ Departamento de Estadística Educativa, Ministerio de Educación y Justicia, Enseñanza Media, 1914-1963, Buenos Aires, 1963, Tomo I, Cuadro Número 56 y Tomo II, Cuadro Número 212.

${ }^{27}$ Departamento de Estadística Educativa...cit. Tomo I, Cuadro Número 53 y Cuadro Número 209.
} 


\section{Cuadro 1}

\begin{tabular}{|c|c|c|c|c|}
\hline \multirow{2}{*}{ Año } & \multicolumn{4}{|c|}{ Alumnos matriculados por año } \\
\cline { 2 - 5 } & \multicolumn{3}{|c|}{ Ciclo Básico Bachiller } & Ciclo superior Magisterio/Bachiller \\
\cline { 2 - 5 } & 1er. año & 2do. año & 3er. año & 4to. año \\
\hline $\mathbf{1 9 4 4}$ & 31.248 & 25.798 & 23.717 & 20.316 \\
\hline $\mathbf{1 9 4 5}$ & 32.760 & 26.049 & 24.065 & 21.003 \\
\hline $\mathbf{1 9 4 6}$ & 33.683 & 27.442 & 23.599 & 20.944 \\
\hline $\mathbf{1 9 4 7}$ & 33.942 & 27.144 & 24.116 & 21.315 \\
\hline $\mathbf{1 9 4 8}$ & 32.791 & 26.340 & 24.011 & 20.775 \\
\hline $\mathbf{1 9 4 9}$ & 34.018 & 25.944 & 23.902 & 21.926 \\
\hline $\mathbf{1 9 5 0}$ & 36.273 & 28.465 & 23.639 & 22.112 \\
\hline $\mathbf{1 9 5 1}$ & 38.545 & 30.577 & 25.371 & 21.628 \\
\hline $\mathbf{1 9 5 2}$ & 43.085 & 32.765 & 27.642 & 23.518 \\
\hline $\mathbf{1 9 5 3}$ & 52.262 & 37.158 & 30.271 & 26.542 \\
\hline $\mathbf{1 9 5 4}$ & 56.781 & 43.158 & 34.087 & 28.320 \\
\hline $\mathbf{1 9 5 5}$ & 63.394 & 46.570 & 39.883 & 32.023 \\
\hline
\end{tabular}

Cuadro de elaboración propia. Fuente: Ministerio de Educación y Justicia, Departamento Estadístico, Enseñanza Media, Tomos I y II (Normal y Media), Buenos Aires, 1964.

La información de este cuadro, demuestra que el aumento matricular experimentado en la educación media durante el peronismo no se produjo en forma homogénea. Por lo contrario, se visualiza que acorde al avance en el trayecto formativo de cada una de las cohortes, los números de inscripciones se reducen marcadamente. Para el caso, sí se toma la cantidad de alumnos que ingresaron al primer año de Ciclo Básico Bachiller entre el período 1946-1952, y se la compara con la cantidad de los alumnos de esas mismas cohortes que lograron acceder al primer año del Ciclo Superior Bachiller y Normal, resulta claro que el índice promedio de desgranamientos asciende a un 30,52\%.

En este contexto, cabe destacar que la información aquí expuesta no pone en juego la veracidad de las investigaciones que sostienen que durante los años del primer peronismo, en las escuelas Bachilleres y Normales, se produjo un crecimiento absoluto en la tasa anual de inscripciones equivalente al 5,9\% y $6,8 \%$ respectivamente. Empero pone en relevancia la necesidad de evaluar estos números en términos relativos. De esta forma resulta posible identificar que mientras la matrícula de ingresantes al primer año experimentó un crecimiento promedio anual del 4,07\%, la misma disminuyó notoriamente en el camino hacia el Segundo Ciclo. 


\section{Cuadro 2}

\begin{tabular}{|c|c|c|c|c|c|c|}
\hline & \multicolumn{6}{|c|}{ Alumnos matriculados por año (colegios nacionales) } \\
\cline { 2 - 8 } Año & Total inscriptos & 1er. año & 2do. año & 3er. Año & 4to. año & 5to. Año \\
\hline $\mathbf{1 9 4 4}$ & $\mathbf{5 8 . 4 3 3}$ & 17.237 & 13.698 & 11.612 & 8.822 & 7.064 \\
\hline $\mathbf{1 9 4 5}$ & $\mathbf{6 1 . 5 3 5}$ & 18.073 & 13.874 & 12.396 & 9.240 & 7.952 \\
\hline $\mathbf{1 9 4 6}$ & $\mathbf{6 5 . 3 9 8}$ & 18.519 & 14.638 & 12.150 & 11.984 & 8.107 \\
\hline $\mathbf{1 9 4 7}$ & $\mathbf{6 6 . 3 7 3}$ & 18.637 & 14.291 & 12.277 & 11.717 & 9.451 \\
\hline $\mathbf{1 9 4 8}$ & $\mathbf{6 7 . 5 8 6}$ & 19.058 & 14.230 & 12.594 & 12.151 & 9.553 \\
\hline $\mathbf{1 9 4 9}$ & $\mathbf{7 1 . 1 3 8}$ & 20.037 & 14.883 & 12.745 & 12.813 & 10.660 \\
\hline $\mathbf{1 9 5 0}$ & $\mathbf{7 5 . 4 0 6}$ & 21.645 & 16.641 & 13.296 & 12.917 & 10.907 \\
\hline $\mathbf{1 9 5 1}$ & $\mathbf{7 8 . 8 0 2}$ & 22.682 & 17.773 & 14.340 & 12.771 & 11.236 \\
\hline $\mathbf{1 9 5 2}$ & $\mathbf{8 3 . 0 3 8}$ & 24.306 & 18.743 & 15.492 & 13.358 & 11.139 \\
\hline $\mathbf{1 9 5 3}$ & $\mathbf{9 2 . 9 3 6}$ & 29.679 & 20.468 & 16.835 & 14.432 & 11.522 \\
\hline $\mathbf{1 9 5 4}$ & $\mathbf{9 9 . 9 1 7}$ & 32.181 & 23315 & 17.961 & 14.773 & 11.687 \\
\hline $\mathbf{1 9 5 5}$ & $\mathbf{1 1 0 . 1 3 1}$ & 35.287 & 26.244 & 21.341 & 14.939 & 12.320 \\
\hline
\end{tabular}

Fuente: Ministerio de Educación y Justicia, Departamento Estadístico, Enseñanza Media, Tomos I y II (Normal y Media), Buenos Aires, 1964.

Cuando se analiza en forma individualizada la situación matricular de las carreras de formación docente y bachillerato, es posible identificar que el desgranamiento experimentado entre el último año del Ciclo Básico y el primero del Ciclo Superior es ampliamente pronunciado en las escuelas Normales. Mientras que en el Cuadro 2 se observa que entre 1946 y 1952 las inscripciones para cuarto año de los colegios nacionales experimentaron un aumento anual promedio del 5,84\%, el Cuadro 3 indica que en los establecimientos donde se formaban los futuros maestros la matriculación se redujo un $1,32 \%$. Es por ello que, frente a esta notoria diferencia, resulta necesario indagar cuáles fueron los motivos por los que, durante este período, una de las carreras con mayor índice de matriculación histórico acabó por reducir su número de inscripciones. ${ }^{28}$

\footnotetext{
${ }^{28}$ Para trabajos vinculados con los niveles de matriculación del Magisterio desde los orígenes del sistema educativo argentino, entre otros ver: ALLIAUD, Andrea Maestros y su historia. Los orígenes del magisterio argentino, Editorial Granica S.A, Buenos Aires, 2010; FIORUCCI, Flavia. "Las escuelas normales y la vida cultural en el interior: apuntes para su historia", en LAGUARDA, Paula y FIORUCCI, Flavia Intelectuales, cultura y politica en espacios regionales (siglo XX), Prohistoria, Rosario, 2012, pp. 131-152; FIORUCCI, Flavia "Maestros para el sistema de educación pública. La fundación de escuelas normales en Argentina (1890-1930)", en Revista Mexicana de Historia de la Educación, vol. II, núm. 3, 2014, pp. 25-45.
} 


\section{Cuadro 3}

\begin{tabular}{|c|c|c|c|c|c|c|c|}
\hline \multirow[b]{2}{*}{ Año } & \multicolumn{7}{|c|}{ Alumnos matriculados por año (escuelas Normales) } \\
\hline & Total inscriptos & 1er. año & 2do. año & 3er. año & 4to. año & 5to. Año & 6to. año \\
\hline 1944 & 49.710 & 14.011 & 12.100 & 12.105 & 11.494 & - & - \\
\hline 1945 & 50.294 & 14.687 & 12.175 & 11.669 & 11.763 & - & - \\
\hline 1946 & 59.618 & 15.164 & 12.804 & 11.449 & 8.960 & 11.241 & - \\
\hline 1947 & 58.172 & 15.305 & 12.853 & 11.839 & 9.598 & 8.577 & - \\
\hline 1948 & 55.206 & 13.733 & 12.110 & 11.417 & 8.624 & 9.322 & - \\
\hline 1949 & 53.625 & 13.981 & 11.061 & 11.157 & 9.113 & 8.313 & - \\
\hline 1950 & 62.477 & 14.628 & 11.824 & 10.343 & 9.195 & 8.840 & 7.647 \\
\hline 1951 & 65.614 & 15.863 & 12.804 & 11.031 & 8.857 & 8.921 & 8.138 \\
\hline 1952 & 63.618 & 18.779 & 14.022 & 12.150 & 10.160 & 8.507 & - \\
\hline 1953 & 74.548 & 22.583 & 16.690 & 13.436 & 12.110 & 9.729 & - \\
\hline 1954 & 85.754 & 24.600 & 19843 & 16.126 & 13.547 & 11.638 & - \\
\hline 1955 & 97.180 & 28.107 & 20.326 & 18.542 & 17.084 & 13.121 & - \\
\hline
\end{tabular}

Fuente: Ministerio de Educación y Justicia, Departamento Estadístico, Enseñanza Media, Tomos I y II (Normal y Media), Buenos Aires, 1964.

\section{Dicotomía democratización-restricción: El paso al Ciclo Superior del Magisterio}

Las acciones estatales emprendidas, entre fines del siglo diecinueve y principios del veinte, con el fin de contar con un cuerpo docente lo suficientemente numeroso para alcanzar todos los rincones del país, se tradujo con el tiempo en un aumento desmesurado de maestros titulados que debió ser controlado. En consecuencia, a partir de la década del treinta, la búsqueda por limitar la matrícula de esta instancia formativa pasó a formar parte de las prioridades gubernamentales, dado que "el exceso de docentes graduados era percibido como alarmante". ${ }^{29} \mathrm{La}$ inexistencia de un examen de ingreso, los escasos requerimientos solicitados al alumno para poder inscribirse en el Magisterio y la existencia de un sistema de asignación de becas muy accesible, eran señalados como los principales motivos de la afluencia masiva de alumnos hacia esta carrera. ${ }^{30}$

Las repercusiones generadas por la sobreproducción de docentes habilitados para ejercer la docencia, mantuvieron sus alcances durante gran

\footnotetext{
29 TEDESCO, Juan Carlos Educación y sociedad en Argentina (1880-1945), Ediciones Solar, Buenos Aires, 1986, p. 256.

${ }^{30}$ FIORUCCI, Flavia "Maestros para...", cit., p. 35.
} 
parte del primer peronismo. ${ }^{31}$ Tal era la notoriedad de la situación que distintos periódicos de la época, incluso ajenos al ámbito educativo, daban cuenta de esta cuestión. ${ }^{32}$ Es por ello que el gobierno nacional acabó encontrándose en la contradictoria posición de tener que compatibilizar la necesidad de restringir el número de ingresantes a las escuelas Normales, con la intención manifiesta de acabar con los condicionamientos que habían caracterizado históricamente al acceso a la educación secundaria.

Frente a la problemática enunciada el peronismo tomó una serie de medidas referidas a las escuelas Normales que, si bien poseían un claro carácter restrictivo, fueron presentadas como una búsqueda por hacer que los establecimientos de formación docente asumieran la condición de institutos profesionales. Un claro ejemplo de ello se evidenció en la decisión de ampliar a tres años el segundo ciclo de estas instituciones. Desde esta perspectiva, la extensión de la duración de la carrera docente permitiría simultáneamente mejorar la calidad de las prácticas formativas del Magisterio y alejar de esa carrera a aquellos jóvenes que, al no tener una verdadera vocación, no se encontrarían dispuestos a cursar un año más de estudio. ${ }^{33}$

Otra estrategia aplicada con el fin de menguar la superproducción de maestros que experimentaba el sistema educativo, consistió en la revalidación de una disposición impulsada durante el gobierno de Edelmiro Farrell a partir de la cual se había implementado como condición taxativa para el ingreso al Nivel Superior del Magisterio, un examen de selección. ${ }^{34}$ En este sentido, para continuar con la construcción argumentativa referida a la intención de mejorar la calidad de este ciclo, el gobierno enunció la necesidad de reformar la impronta que había caracterizado las evaluaciones de ingreso desde el momento de su instauración. ${ }^{35}$ Se consideraba fundamental que estas instancias evaluativas comenzaran a profundizar en el carácter vocacional y de aptitud

\footnotetext{
${ }^{31}$ La problemática situación que generaba la sobreproducción de maestros es detallada, entre otras circulares, en: Paulino Mussacchio, "Circular No 93", 31 de octubre de 1947, A.R.S.P.

32 Para el caso, entre otros, ver: "La enseñanza normal", en La Nación, Buenos Aires, 13 de octubre de 1947; "Número de Estudiantes normalistas", en La Prensa, Buenos Aires, 26 de octubre de 1947; "Vocación y aptitud profesional del Magisterio" en El Mundo, 13 de octubre de 1947; “Modificaciones en la enseñanza normal”, en El Pueblo, 19 de octubre de 1947.

33 Para el caso de la extensión del segundo ciclo de las escuelas normales ver FONTE, Leonardo "Hacia una nueva configuración del Magisterio. Las políticas educativas peronistas y la formación docente (1947-1955)", en Cuadernos Chilenos de Historia de la Educación, vol. 4, núm. 6, 2016, pp. 22-24.

${ }^{34}$ Decreto núm. 4.942, 15 de febrero 1946.

${ }^{35}$ Para el análisis de las formas de estructurar los exámenes de ingreso, previa aprobación del Decreto núm. 31.653, ver entre otros: Presidencia de la Nación Argentina, Decreto 4942/46, comunicado a los Magisterios Nacionales y Adscriptos mediante la "Circular Escolar No 10" con fecha 19 de febrero de 1946, Archivo Histórico del Colegio Nacional Domingo Faustino Sarmiento (en adelante ADFS).
} 
profesional de los jóvenes aspirantes. Desde entonces con el examen, además de contemplar aspectos meramente teóricos, también se comenzaron a juzgar cuestiones básicas que a futuro determinarían las prácticas docentes cotidianas de los ingresantes. Entre ellas se destacaba la elocución fácil, la propiedad y claridad en la expresión, el timbre natural de la voz, el tono agradable y la variedad de léxico. ${ }^{36}$

Las autoridades nacionales, intentando alejarse de cualquier posibilidad de vinculación entre su política escolar y la idea de restricción, acabaron afirmando que la aplicación de la evaluación de aptitud también resultaba favorable a las necesidades de los estudiantes. Se sostenía entonces que los jóvenes que no se encontraran en condiciones de acceder a una vacante para cursar su trayecto de formación docente, no serían marginados del sistema educativo. ${ }^{37}$ Por lo contrario, el Estado se estaba encargando de orientar a estos aspirantes hacia otro tipo de estudios más en consonancia con sus aptitudes, evitando de esta forma "el fracaso individual que [entrañaba] el Magisterio para quien lo [ejercía] sin íntima afición y [...] el malestar social, lesivo de la cultura, que tal género de maestros adventicios [comportaba]". ${ }^{38}$ Es decir que el objetivo principal del Estado, tal como se explicitaría posteriormente en la Constitución del año 1949, residía en la intención de guiar a los jóvenes hacia actividades para las que poseyeran aptitudes y capacidades naturales, con el fin de que la adecuada elección profesional redundara en su propio beneficio y en el de la sociedad. ${ }^{39}$ De esta forma el otorgamiento del título de Bachiller Elemental le permitía al Estado redireccionar el trayecto formativo de los alumnos, que no hubieran podido aprobar el examen de ingreso, hacia las escuelas nacionales o bien a institutos de capacitación de índole comercial, industrial o militar.

En lo concreto la aplicación de las estrategias restrictivas implementadas en el Ciclo Superior del Magisterio, se tradujo en una clara disminución de la matrícula en el momento en que los estudiantes debían comenzar a especializarse en su formación docente. El constante descenso matricular que se experimentó en el paso al ciclo superior, desde el momento en que se

\footnotetext{
${ }^{36}$ La caracterización de los aspectos aptitudinales, que debía contemplar la evaluación de selección fueron profundizados en el Decreto núm. 37.459 del 9 de diciembre de 1948. Para el análisis de las características del examen de ingreso y la metodología de su aplicación, ver FONTE, Leonardo "Hacia una nueva configuración...", cit., pp.16-19.

${ }^{37}$ En caso de desaprobación del examen de ingreso, el aspirante ya no podría contar con otra posibilidad para ingresar al Segundo Ciclo de las escuelas Normales.

38 Decreto núm. 31.653, 10 de octubre de 1947. Mariano Plotkin refiere en términos de "segmentación negativa", al hecho de que a los estudiantes fueran alejados del nivel secundario tradicional, siendo redireccionados hacia otro tipo de estudios. PLOTKIN, Mariano Mañana es San Perón..., cit., pp. 160-161.

${ }^{39}$ Presidencia de la Nación Argentina, "Constitución de la Nación Argentina" (1949), Artículo 3 .
} 
comenzaron a aplicar los exámenes hasta el año 1953 inclusive, alcanzó un promedio anual del $18,24 \% .{ }^{40}$ En tal sentido, se debe contemplar que este desgranamiento no puede ser entendido solo a partir del análisis de variables externas a las intenciones gubernamentales. Por lo contrario, es necesario identificar que esta situación mantuvo un claro correlato con la decisión del gobierno por controlar la producción de maestros habilitados para dar clase en las escuelas primarias.

\section{Hacia la restructuración pedagógica del Ciclo Básico Bachiller}

Los años previos a 1950 son señalados, por aquellos que estudian la política educativa peronista en clave de discontinuidad, como un período que se caracterizó por haber sentado las bases que posteriormente garantizaron el éxito de los mecanismos destinados a la generación de un consenso político propio de un gobierno de carácter autoritario. ${ }^{41}$ Consecuentemente la democratización del acceso a la enseñanza y la búsqueda de una mayor centralización del sistema educativo, son identificadas como acciones que le permitieron al gobierno peronista alcanzar sus objetivos. ${ }^{42}$ Frente a estas aseveraciones resulta necesario preguntar si es posible afirmar que la política educativa peronista, aplicada durante los años de su primera gestión, puede ser reducida a la idea de adoctrinamiento, o si por lo contrario puede ser pensada como el producto de una reelaboración más compleja de los postulados propios de las prácticas escolares vigentes hasta el momento.

\section{En búsqueda de la identificación de los problemas de la educación media}

Tal como lo afirma Miguel Somoza Rodríguez el peronismo buscó generar, desde el campo de la educación, una subversión cognitiva que produjera una transformación de las representaciones, las percepciones y las clasificaciones de lo real admitidas hasta ese momento. ${ }^{43}$ Para el caso se consideraba que en las escuelas no resultaba adecuado seguir formando a generaciones de argentinos

\footnotetext{
${ }^{40}$ La vigencia del dispositivo de selección, para el ingreso al Ciclo Superior del Magisterio, se extendería hasta el año 1952. Decreto núm. 12.741, 10 de diciembre de 1952.

${ }^{41}$ PLOTKIN, Mariano Mañana es San Perón..., cit., pp. 157-169; REIN, Mónica y REIN, Raanan "Populismo y educación...", cit., p. 56.

42 Para el caso del ordenamiento institucional del sistema educativo argentino, entre otros, ver: BERNETTI, Jorge y PUIGGRÓS, Adriana Peronismo: Cultura... cit., pp. 250-258; CAMMAROTA, Adrián "El Ministerio de Educación durante el peronismo: ideología, centralización, burocratización y racionalización administrativa (1949-1955)", en Revista Historia de la Educación Latinoamericana, vol. 15, 2010, pp. 63-92.

43 SOMOZA RODRÍGUEZ, Miguel "Una mirada vigilante, educación del ciudadano y hegemonía en argentina (1946-1955)", en CUCUZZA, Héctor Estudios de historia de la educación durante el primer peronismo (1943-1955), Editorial los libros de riel, Buenos Aires, 1997, p. 12.
} 
que se encontraran aferradas a conceptos que ya no mantenían un correlato con la realidad de la Nación. El funcionamiento de una nueva argentina requería de la existencia de nuevos hombres, y estos solo podían ser forjados en un sistema educativo completamente renovado. ${ }^{44}$

En este contexto, la intención del gobierno residía en que sus reformas no se anclaran, tal como había ocurrido desde los orígenes del sistema educativo, en supuestos teóricos aislados de la realidad Argentina. ${ }^{45} \mathrm{Al}$ entender de Juan Domingo Perón, los métodos pedagógicos propuestos por Pestalozzi o por cualquier otro pedagogo internacional no podían lograr que los estudiantes aprendieran a conocer y amar a su país. La única forma de cambiar "genuinamente" al sistema educativo nacional residía en la posibilidad de implementar un tipo de enseñanza pensada por y para los argentinos. ${ }^{46}$

En el caso del nivel medio, la intención de crear un método pedagógico local implicó la necesidad de recurrir a la colaboración de los docentes. La experiencia cotidiana en contacto con el aula, convertía a los profesores en voces autorizadas al momento de realizar aportes en este proceso de renovación. Es por ello que la intención manifiesta del gobierno se focalizó en que estos agentes educativos pudieran puntualizar las fallas que perjudicaban el pleno desarrollo de su labor cotidiana, y en consecuencia que también pudieran señalar las posibles soluciones a dichas problemáticas. ${ }^{47}$

La participación de los profesores en las reformas de la educación secundaria, tuvo lugar rápidamente desde los primeros momentos de la gestión peronista. El 8 de julio de 1946, el Ministerio de Instrucción Pública hizo llegar a todos los establecimientos oficiales de su dependencia una encuesta que los

\footnotetext{
${ }^{44}$ Discurso enunciado por Juan Domingo Perón el 4 de agosto de 1947, en el Teatro Colón durante el acto organizado por docentes secundarios, en Ministerio de Justicia e Instrucción Pública, La educación nacional, 1947, pp. 4-5, BNM.

${ }_{45}$ Para el análisis de las propuestas pedagógicas que signaron el funcionamiento del sistema educativo argentino desde sus orígenes, entre otros, ver: CARLI, Sandra Niñez, pedagogía y política. Transformaciones de los discursos acerca de la infancia en la historia de la educación argentina 1880-1955, Miño y Davila, Buenos Aires, 2002, pp. 96-227; PUIGRRÓS, Adriana ¿Qué pasó en la educación argentina? Breve historia desde la conquista al presente, Galerna, Buenos Aires, 2003, pp. 91-110; LIONETTI, Lucía La misión política de la escuela pública. Formar ciudadanos de la república (1870-1916), Miño y Dávila, Buenos Aires, 2010, pp. 75-105.

46 Discurso enunciado por Juan Domingo Perón el 19 de diciembre de 1947, en Casa de Gobierno frente a inspectores de enseñanza y visitadores de las escuelas de todo el país. "El general Perón habla al Magisterio", en Monitor de la Educación Común, Buenos Aires, Enero-Abril de 1948, pp. 901-904.

47 Para el caso ver: Notificación enviada por el Subsecretario de Instrucción Pública Jorge Arizaga, el 8 de julio de 1946, a los directores de las escuelas de educación media, Archivo Histórico del Colegio Nacional Mariano Acosta (en adelante AMA). Resolución disponiendo que la redacción de los programas analíticos estaría a cargo de los profesores en las asignaturas que dictan, 21 de febrero de 1948, AMA.
} 
directores debían hacer completar al cuerpo docente de sus instituciones. La realización de ese cuestionario tenía como objetivo recopilar información sobre los problemas que afectaban a la enseñanza media del país.

La encuesta incluía una serie de preguntas, con una clara impronta escolanovista, que versaban sobre los Planes y Programas de estudios correspondientes a las distintas materias que se dictaban en la escuela secundaria. ${ }^{48}$ En ellas se pretendía identificar si la estructuración de los contenidos vigentes y la forma de concebir la enseñanza, atentaban contra el funcionamiento del nivel en cuestión. Es por ello que varias de las consultas giraban en torno a la intención de conocer si la excesiva extensión de los programas era la causa de una enseñanza de carácter verbalista y libresca; si la enseñanza impartida uniformemente sin considerar aptitudes y modalidades peculiares de cada alumno era un contrasentido pedagógico y si la excesiva preocupación por impartir conocimiento conducía a olvidar, con frecuencia, el sentido formativo que debía tener el aprendizaje. ${ }^{49}$

En el archivo histórico del Colegio Nacional Roque Sáenz Peña, se encuentran documentados los informes de cuarenta y seis docentes de la institución, que respondieron esta encuesta. ${ }^{50}$ Independientemente del rango de especificidad que caracteriza a cada materia en particular, en estos registros prima como opinión generalizada que la extensión de los programas impedía que se desarrollara un conocimiento concreto y profundo de los temas trabajados. En tal sentido, se identificaba que el problema no residía en que no fuera posible dictar la totalidad de las bolillas estipuladas en los programas. El inconveniente se focalizaba en que el volumen de contenidos no permitía que los estudiantes pudieran incorporar tantos conocimientos.

A casi un año de la circulación de las encuestas realizadas a los docentes, el Subsecretario de Instrucción Jorge Arizaga, en un discurso titulado "La enseñanza media en el Plan de Gobierno", sintetizó la identificación de los

\footnotetext{
${ }^{48}$ Para el movimiento de la escuela nueva, entre otros, ver: GVIRTZ, Silvina Escuela nueva en Argentina y Brasil: visiones comparadas, Miño y Dávila, Buenos Aires, 1996; CARUSSO, Marcelo "¿Una nave sin puerto definitivo?: antecedentes, tendencias e interpretaciones alrededor del movimiento de la escuela nueva", en DUSSEL, Inés La escuela como máquina de educar: tres escritos sobre un proyecto de la modernidad, Paidós, Buenos Aires, 2001, pp. 93-134.

${ }^{49}$ Copia fiel de la encuesta confeccionada por el Ministerio de Justicia e Instrucción Pública, 3 de julio de 1946, ARSP.

50 "Informes realizados por los docentes del Colegio Nacional Roque Sáenz Peña" (1946), ARSP. En el resto de los archivos escolares consultados no se encontró esta documentación. La ausencia de dichos informes no significa que en estas escuelas no se haya realizado la encuesta. Empero si da cuenta de la cantidad de materiales que se fueron perdiendo a lo largo de los años, en cada uno de estos archivos, como producto de una conservación deficiente, por la destrucción provocada por incendios e inundaciones, o a causa del extravió en las distintas mudanzas que experimentaron estos establecimientos.
} 
problemas que se habían detectado en el desarrollo de las prácticas educativas del nivel secundario. ${ }^{51}$ En este sentido, cabe destacar que su desarrollo argumentativo coincidió sin residuos con las respuestas esbozadas por los docentes del Colegio Roque Sáenz Peña. La identificación del problema, de esta instancia formativa, residía según su propio discurso en el carácter teórico e intelectualista propio de una educación positivista heredada del último tercio del siglo XIX. De esta forma, la solución propuesta giraba en torno a una sola posibilidad: reformar y actualizar los Programas de estudios.

\section{Las Reformas de los Planes y Programas de estudio para el Ciclo Básico Bachiller}

La intención de reformar los Planes y Programas de estudios de las escuelas medias, respondía a una doble necesidad.52 Inicialmente, se entendía que resultaba fundamental "racionalizar la enseñanza y adoptarla a nuevos principios formativos". De esta forma la orientación positivista y enciclopedista que había caracterizado la enseñanza secundaria, debía dar paso a una formación que priorizara el aprendizaje por sobre el dictado compulsivo de contenidos. $^{53}$ En segundo término, se explicitaba que el reconocimiento del derecho a la obtención del título Bachiller Elemental, exigía una restructuración del Plan de estudios del Ciclo Básico. El éxito de las reformas dependía de que estas fueran aplicadas en los cursos con mayor índice de matriculación. Por tal motivo frente al nivel de desgranamiento experimentado por las distintas cohortes, acorde avanzaban en su trayecto formativo, se identificaba como prioritario centrar las modificaciones en los primeros años de la educación media. ${ }^{54}$

La primera parte de la reforma de los Planes y Programas aplicada en el nivel medio, por el peronismo, tuvo lugar en el año $1948 .{ }^{55}$ Desde entonces se

\footnotetext{
${ }^{51}$ Dirección General de Informaciones, Biblioteca y Estadística, Boletín de Ministerio de Justicia e Instrucción Pública de la Nación Argentina, 1947. El análisis sobre este discurso es profundizado en PANELLA, Claudio “Una aproximación a la enseñanza...", cit. pp. 142-143.

${ }^{52}$ Para un análisis del balance realizado por el peronismo en relación a la necesidad de reformar las características de la educación media, ver PANELLA, Claudio "Una aproximación...", cit., pp. 141-143.

53 Decreto núm. 5114, 20 de febrero 1948.

${ }^{54}$ Decreto núm. 5114, 20 de febrero 1948. La intención de centrar los cambios de los Planes y Programas de estudios en el Ciclo Básico Bachiller, mantuvo su vigencia en la reforma de 1952. A partir de ese año se incluyó, en los tres primeros años de la educación media, la asignatura emblema de lo que fuera peronización de los contenidos: Cultura de la Ciudadanía. Sobre el tema, ver SOMOZA RODRÍGUEZ, Miguel Educación y política..., cit., pp. 234-278.

55 Resolución de la Secretaria de Educación designando las comisiones técnicas para la redacción de los programas sintéticos de los tres cursos del Ciclo Básico, 20 de febrero de 1948, BNM.
} 
destacó como principal cambio la inclusión en el Ciclo Básico Bachiller de dos asignaturas. La implementación de la enseñanza de latín, para los tres cursos del nivel en cuestión, fue visualizada como una forma de poner en contacto a los jóvenes con las fuentes originarias de la civilización de occidente que nutría la cultura local. Por otro lado, teniendo en cuenta que la enseñanza media debía contribuir a formar conciencia nacional, la otra materia incorporada fue Historia Argentina en tercer año. ${ }^{56}$

En búsqueda de que la renovación educativa fuera orientada por los criterios de quienes trabajaban cotidianamente en las escuelas, la Secretaria de Educación solo definió, provisoriamente, los programas de las asignaturas correspondientes al primer año. ${ }^{57}$ La realización de la reforma de los contenidos que se enseñarían en el Ciclo Básico Común fue encomendada a cinco comisiones técnicas que, nucleadas en torno a materias afines, fueron conformadas por docentes, rectores e inspectores. ${ }^{58}$ Un año más tarde, el trabajo producido por estas comisiones, fue revisado y aprobado por los inspectores de la Dirección General de Enseñanza Secundaria, Normal y Especial dando paso de esta manera a la concreción de la reforma de 1949. ${ }^{59}$ Reforma que excediendo la gestión de Oscar Ivanissevich, mantuvo vigencia durante los primeros años del ejercicio de funciones de Armando Méndez San Martín como Ministro de Educación.

El Plan de estudios definitivo del Ciclo Básico Común continuó profundizando la intención de aumentar la cantidad de contenidos referidos al pasado nacional que se debían dictar en el nivel en cuestión, es por ello que se incluyeron nuevos cambios en lo referido al ordenamiento de las materias vinculadas a esta temática. En los dos primeros años de cursada se incorporó el dictado de la asignatura Historia Argentina. Razón por la cual los programas correspondientes a dicha materia pasaron a incluir, para el caso de primer año, el estudio desde las culturas precolombinas hasta la revoluciones de Chuquisaca y La Paz, y para el segundo año, la enseñanza del período que comprende desde la Revolución de Mayo hasta la aprobación de la Ley Sáenz Peña. ${ }^{60}$ De esta forma se puede observar que, a diferencia de lo enunciado por

\footnotetext{
${ }^{56}$ Secretaria de Educación de la Nación, "Programas para los cursos del Ciclo Básico común a los estudios de bachillerato y magisterio" (1948), 1-2, BNM.

57 Resolución de aprobación del anteproyecto de los Programas sintéticos de primer año del Ciclo Básico y del cuarto del Ciclo Superior Magisterio, 23 de marzo de 1948, BNM.

58 Resolución de la Secretaria de Educación designando las comisiones técnicas para la redacción de los programas sintéticos de los tres cursos del Ciclo Básico, 20 de febrero de 1948, BNM.

${ }^{59}$ Resolución de la Secretaria de Educación aprobando los programas para los Ciclos Básicos Bachiller, 8 de marzo de 1949, BNM.

${ }^{60}$ Ministerio de Educación de la Nación, "Planes y programas de estudios; ciclo básico $1^{\circ}, 2^{\circ} \mathrm{y}$ 3er año; Curso Superior del Magisterio $4^{\circ}, 5^{\circ}$ y $6^{\circ}$ año" (1949), 29-34, BNM. Desde entonces, la
} 
Somoza Rodríguez, la reinterpretación de las culturas prehispánicas como elementos que configuraron posteriormente a los Estados Modernos, lejos de ser una novedad de los Planes y Programa de estudio de 1952, encontró su origen en la reforma curricular de $1949 .{ }^{61}$

La redacción de los nuevos programas de Historia Argentina estaba concebida con el fin de que los contenidos pudieran ser estudiados y repasados a lo largo del curso lectivo. Se recomendaba a los profesores completarlos íntegramente uno o dos meses antes de terminar las clases, a fin de dedicar el último período a un repaso que sirviera para presentar "al alumno una visión de conjunto de nuestra emancipación y organización nacional, sin clasificaciones, fechas y otros pormenores fatigosos". ${ }^{62}$ En el mismo sentido, dado que se entendía que la visión histórica de los manuales resultaba "harto precaria", se instaba al docente a enriquecer sus clases con elementos didácticos y la lectura de obras históricas, documentos, periódicos y demás fuentes. ${ }^{63}$

La impronta anti positivista que caracterizó a la reforma que entró en vigencia desde 1949, implicó que los programas señalaran que la enseñanza debía ser funcional a las necesidades de los estudiantes. ${ }^{64}$ En consecuencia, por ejemplo, en el programa de Matemáticas se enunciaba que los contenidos se habían orientado a la eliminación de "todo exceso de formalismo, contrario a la mentalidad del adolescente, ofreciendo al profesor la posibilidad de alejarse de la norma rígidamente preestablecida, para encarar la enseñanza [...] adaptándola a la manera de ser del educando". ${ }^{65}$ Por otro lado, y en el mismo sentido, como norma general para el dictado de todas las materias se establecía que al momento de impartir su clase, los docentes debían tener presente las

asignatura Historia Antigua y Medieval pasó de ser dictada en tercer año, cuando anteriormente correspondía a primero, mientras que Historia Moderna y Contemporánea, que formaba partes del programa de segundo, fue incluida en el Ciclo Superior.

${ }^{61}$ SOMOZA RODRÍGUEZ, Miguel Educación..., cit., pp. 236-249.

${ }^{62}$ Ministerio de Educación de la Nación, "Planes y programas...", cit., p. 34.

${ }^{63}$ Los rasgos de continuidad que evidenciaron los libros de texto utilizados durante el peronismo, en relación al período anterior, son analizados entre otros en WAINERMAN, Catalina y HEREDIA, Mariana ¿Mamá amasa la masa? Cien años en los libros de la escuela primaria, Editorial Belgrano, Buenos Aires, 1999.

${ }^{64}$ La impronta antipositivista enunciada por el gobierno, también contemplaba un aspecto espiritual que se evidenció en la revalidación de la enseñanza de educación religiosa. Para el tema ver: PITELLI, Cecilia y SOMOZA RODRÍGUEZ, Miguel "La enseñanza religiosa en la escuela pública 1943-1955", en Revista Argentina de Educación, núm. 20, 1993, pp. 65-82; BIANCHI, Susana "Catolicismo y peronismo: la educación como campo de conflicto" en Anuario del Instituto de estudios Histórico-sociales, núm. 11, 1996, pp.147-178. Sobre la formación religiosa en la educación media ver PANELLA, Claudio "Una aproximación...", cit., pp. 144146.

${ }^{65}$ Ministerio de Educación de la Nación, "Planes y programas de estudios; Ciclo Básico $1^{\circ}, 2^{\circ}$ y 3er año; Curso Superior del Magisterio $4^{\circ}, 5^{\circ}$ y $6^{\circ}$ año" (1949), 39, BNM 
características psicológicas de los alumnos que tenía a cargo: "educandos de doce a catorce años, en los umbrales de la adolescencia, o en pleno proceso, que abordan un nuevo ciclo de actividad intelectual". Es por ello que se sugería no romper bruscamente con las normas de enseñanza de la educación primaria, y se instaba al profesor a colaborar para que el ingresante a primer año pudiera ir generando lentamente nuevos hábitos de estudio propios del nivel secundario. ${ }^{66}$

\section{La Sociedad Pedagógica Argentina}

La Sociedad Pedagógica Argentina se constituyó como una entidad mediante la que el Ministerio de Educación buscó continuar el proceso de reformas iniciado tempranamente por el gobierno peronista en el sistema educativo. En tal sentido, el hecho de que la fecha de inicio de sus actividades haya tenido lugar a pocos meses de la aplicación del Plan de estudio de 1949 habla de una continuidad en la búsqueda por redefinir los métodos y los objetivos de la enseñanza argentina. ${ }^{67}$ Por otro lado, el lugar que se le asignó a los docentes en su funcionamiento, evidenció nuevamente la intención gubernamental de permitir que los trabajadores de la educación se constituyeran en agentes activos frente a la necesidad de continuar modificando las características de la educación nacional.

Cabe destacar que, si bien el nombre de la Sociedad Pedagógica no refería en forma exclusiva al nivel secundario, el propio Ministro de Educación fue el encargado de enfatizar que el principal motivo por el que se había constituido dicha entidad residía en los problemas que aún presentaba el funcionamiento de la escuela media. Al entender de Ivanissevich, mientras que la enseñanza elemental podía seguir funcionando sin modificaciones por al menos otros cinco años, este plazo no podía hacerse extensivo a la educación secundaria. ${ }^{68}$ Es por ello que resultaba fundamental dar una solución definitiva a las problemáticas propias de este nivel educativo.

En pos de garantizar su buen funcionamiento, este organismo se encontraba conformado por una comisión directiva regida por el Rector del

\footnotetext{
${ }^{66}$ Ministerio de Educación de la Nación, "Planes y programas de estudios; Ciclo Básico $1^{\circ}, 2^{\circ} \mathrm{y}$ 3er año; Curso Superior del Magisterio $4^{\circ}, 5^{\circ}$ y $6^{\circ}$ año" (1949), 15, BNM

${ }^{67}$ En su trabajo Consideraciones sobre la adolescencia, Rafael Gagliano identifica a esta continua búsqueda por transformar la educación secundaria como una incapacidad del peronismo por cambiar profundamente las prácticas educativas del nivel medio. GAGLIANO, Rafael "Consideraciones sobre la adolescencia en el período", en PUIGGRÓs Adriana y CARLI, Sandra Discursos pedagógicos e imaginario social en el peronismo (1945-1955), Galerna, Buenos Aires, 1995, p. 201.

68 Sociedad Pedagógica Argentina, "Publicación No1", 26 de Agosto de 1949, 2-3, BNM. Una copia del discurso de inauguración de la Sociedad Pedagógica Argentina, fue encontrada en el Archivo Histórico del Colegio Nacional Mariano Acosta.
} 
Instituto Nacional del Profesorado Secundario, Juan Emilio Cassani. ${ }^{69}$ Esta comisión no gozaba de poder de decisión per se, sino que era la encargada de organizar los encuentros, definir los tópicos de debate, publicitar las acciones de la Sociedad y publicar las actas de cada una de las reuniones realizadas. Dichas tareas, que tenían mayoritariamente un carácter de difusión, respondían principalmente a la necesidad de que la convocatoria llegara a todos los docentes interesados en participar.

La Sociedad Pedagógica se encontraba abierta a los aportes de los integrantes del sistema educativo argentino, dado que se entendía que solo a partir de una colaboración plena se podría cumplir tamaña empresa. ${ }^{70} \mathrm{Al}$ respecto, si bien resulta complejo afirmar taxativamente que en esta Sociedad se produjo una participación plena y libre de todos los docentes, es posible observar rasgos de pluralidad de pensamiento en diversos debates que tuvieron lugar, entre los participantes, a lo largo de las distintas reuniones. Un claro ejemplo de ello se visualiza en un intercambio de ideas desarrollado durante el primer encuentro, entre una docente expositora identificada como la Señora Muñoz y el presidente de la Sociedad Pedagógica Juan Emilio Cassani, en torno a diferentes visones respecto a cómo se debía estructurar el paso de los estudiantes desde el nivel primario al secundario. ${ }^{71}$

Tanto los docentes que ejercían sus funciones frente al aula, como aquellos que se desempeñaban como directivos e inspectores, podían participar de forma directa en las reuniones, opinando en relación a lo expuesto por los oradores, o bien mediante el envío de trabajos que serían leídos por el presidente de la Comisión y luego expuestos a debate. De la misma forma eran los participantes de las de las reuniones, quienes mediante sus votos acreditaban la legitimidad de las conclusiones que se extrajeran de cada uno de los encuentros. Dado que la sociedad en cuestión poseía un carácter consultivo, las conclusiones alcanzadas se debían poner a disposición de las autoridades

\footnotetext{
${ }^{69}$ Desde su origen, y hasta el cese de sus funciones, la comisión de la Sociedad Pedagógica Argentina se encontró formada por: María Susana Dessein de Barraza como Secretaria y por Pedro L. Comi, el Ingeniero José Pagés, el Profesor Félix Natt Kemper y el Profesor Miguel A. Borau como vocales. Sociedad Pedagógica Argentina, "Publicación N 1", 26 de agosto de 1949, BNM. Sobre la posición escolanovista de Juan Emilio Cassani, entre otros, ver: BERNETTI, Jorge y PUIGGRÓS, Adriana Peronismo: Cultura..., cit., 155-171.

${ }^{70}$ La Sociedad Pedagógica notificaba la fecha y las formas de funcionamiento de cada uno de sus encuentros a través de invitaciones enviadas a los colegios. Para el caso, entre otros, ver: Invitación de la Sociedad Pedagógica Argentina, 1 de septiembre de 1949, ARSP. Invitación de la Sociedad Pedagógica Argentina, 22 de octubre de 1949, ARSP.

${ }^{71}$ Sociedad Pedagógica Argentina, "Publicación No1", 26 de agosto de 1949, 11-13, BNM. Para otros casos en los que se observan divergencias interpretativas respecto a cómo estructurar las reformas del nivel secundario ver: Sociedad Pedagógica Argentina, "Publicación No3", 10 de octubre de 1949, 11-13, BNM. Sociedad Pedagógica Argentina, "Publicación No4", 3 de noviembre de 1949, 84, BNM.
} 
educativas para que fueran estas quienes tomaran la decisión de aplicar, o no, las medidas propuestas.

Durante la primera sesión que puso en funcionamiento a esta entidad, los temas a debatir giraron en torno a la coordinación didáctica de la enseñanza primaria con la enseñanza media. Se planteaba la necesidad de revertir la experiencia traumática que representaba para el alumno el paso de la escuela elemental hacia una experiencia completamente diferente representada por el segundo ciclo de la enseñanza. Situación que se reflejaba en el alto porcentaje de frustración de los alumnos, y consecuentemente en el abandono de su trayecto educativo. Se concluyó, entonces, que resultaba fundamental asimilar los contenidos y las prácticas pedagógicas didácticas de los dos últimos años del primario con los dos primeros del nivel secundario. De esta forma, delinear un proceso de transición más amable, sería favorable al sostenimiento de la matrícula escolar. ${ }^{72}$

En la segunda reunión, llevada a cabo el 19 de septiembre de 1949, el tópico a debatir se basó en torno a la necesidad de revisar las formas didácticas que caracterizaban al nivel medio de la educación. En búsqueda de la aplicación de una didáctica de carácter nacional, se propuso entonces la creación de un "Gran Departamento Didáctico". Este Departamento sería de carácter consultivo y asesor frente a todos los problemas referentes a la educación e instrucción, y se encargaría también del estudio de los problemas de la política educacional argentina. ${ }^{73}$

Las tres últimas reuniones, de la Sociedad Pedagógica, fueron destinadas a un tópico común que consistió en determinar cómo se debía estructurar la escuela secundaria frente a la necesidad de formar una "nueva juventud argentina". ${ }^{74}$ Consecuentemente se propuso intensificar el principio de unidad formativa que regía al Ciclo Básico Bachiller, estableciendo un Ciclo Común para todas las orientaciones de las escuelas secundarias. Por otro lado se identificó como necesario estudiar las características y las necesidades de los adolescentes argentinos, tanto en su aspecto general como en su carácter individual, a fin de atenderlas en la medida de lo posible y contribuir con eficacia a la formación de su personalidad. Es por ello que se estableció que en la primera reunión del año 1950 se debía continuar profundizando en el análisis de este tópico ahondando en la formación de la personalidad de la juventud argentina, en el estudio psicopedagógico de los alumnos y en el problema vocacional de los adolescentes.

\footnotetext{
72 Sociedad Pedagógica Argentina, "Publicación No1", 26 de agosto de 1949, BNM

73 Sociedad Pedagógica Argentina, "Publicación No2", 19 de septiembre de 1949, BNM.

${ }^{74}$ Sociedad Pedagógica Argentina, "Publicación No3", 19 de octubre de 1949, BNM. Sociedad Pedagógica Argentina, "Publicación No4", 3 de noviembre de 1949, BNM. Sociedad Pedagógica Argentina, "Publicación No5", 1 de diciembre de 1949, BNM.
} 
El funcionamiento de esta entidad acabó repentinamente luego de la reunión del $1^{\circ}$ de diciembre de 1949 . Para el caso, si bien no se encuentran registros que den cuenta del motivo por el cual esta entidad dejó de funcionar, es posible adjudicar el fin de sus funciones a la llegada del doctor Armando Méndez San Martín al Ministerio de Educación de la Nación. El nuevo funcionario nacional, a partir de las decisiones tomadas desde su gestión, dio claras cuentas de su intención de cambiar decisivamente el estilo impuesto por Ivanissevich al organismo que se encontraba ahora a su cargo. ${ }^{75}$ Empero se debe destacar que, a pesar de esta intención, los Planes y Programas de estudios reformados en 1949 continuaron manteniendo vigencia hasta el año 1952 y que incluso en la reforma curricular realizada durante este año, es posible identificar la persistencia de propuestas realizadas, en su momento, en las reuniones de la Sociedad Pedagógica Argentina. Da cuenta de ello, por ejemplo, la igualación que se estableció para los primeros tres primeros años de todas las modalidades de la educación secundaria, a partir la conformación de un mismo Ciclo Básico Común, o bien en la identificación del problema que generaba el cambio brusco que acontecía en el paso de la escuela primaria a la secundaria y que buscó ser solucionado coordinando la labor de todos los profesores, de cada curso, alrededor de un núcleo de atracción hacia el cual debían tender todas las actividades escolares. ${ }^{76}$

La formación de la Sociedad Pedagógica Argentina se constituyó en la última de varias experiencias, iniciadas durante la gestión de Ivanissevich, que tuvieron por objetivo modificar las prácticas pedagógicas propias del Ciclo Básico Bachiller. En este sentido el derrotero del accionar reformista llevado a cabo por el peronismo, durante sus primeros años de gobierno, permite dar cuenta de uno proceso de reconfiguración de las prácticas educativas que no puede circunscribirse a la idea de adoctrinamiento. Paralelamente, la estructuración de distintos canales de participación con los que el gobierno instó a la colaboración de los docentes en este proceso de reformas, permite matizar las ideas que refieren que, durante este período, los educadores acabaron siendo interpelados solo como ejecutores pasivos de las políticas educativas peronistas.

\section{A modo de conclusión}

Los estudios que interpelan al primer peronismo como un fenómeno político que modificó profundamente el devenir histórico de La República Argentina

\footnotetext{
${ }^{75}$ Para los cambios experimentados en el Ministerio de Educación con la llegada de Méndez San Martín, entre otros ver PLOTKIN, Mariano Mañana es San Perón..., cit., pp. 169-174.

${ }^{76}$ Ministerio de Educación de la Nación, "Plan de Estudios del Ciclo Básico de la Enseñanza Secundaria y de las Escuelas de Comercio" (1952), BNM.
} 
han encontrado en los análisis de la cuestión educativa, entre los años 1946 y 1955, un claro punto de apoyo a partir del cual reafirmar sus conclusiones. En este sentido las transformaciones operadas en el ámbito escolar durante el período en cuestión son foco de diversos trabajos que buscan identificar, desde distintas perspectivas, cómo la llegada de Juan Domingo Perón a la Presidencia de la Nación inauguró una nueva etapa en el desarrollo del sistema educativo nacional. Empero, se observa que las divergencias analíticas que evidencian estos múltiples estudios, encuentran sus matices en algunos puntos en común que estructuran la mayor parte de los trabajos. En primera instancia, los análisis en relación a esta temática se centran en el nivel primario de la educación, dejando de esta forma un marcado vacío historiográfico en lo que refiere al estudio de la configuración de la educación secundaria a lo largo de estos años. Por otro lado, se observa, que la mayor parte de las investigaciones referidas a la cuestión escolar, durante el primer peronismo, se estructuran en el binomio conceptual democratización y adoctrinamiento.

Para establecer los alcances del proceso de restructuración del nivel medio de la educación, para las escuelas de Capital Federal y de los territorios Nacionales, entre los años 1946 y 1952, en el presente trabajo se busca matizar aquellos conceptos que acabaron constituyéndose en prismas analíticos desde los que diversos investigadores han desarrollado sus estudios. En tal sentido se debe destacar que lejos de pretender desconocer los cambios efectuados en el campo educativo durante este período, desde el presente trabajo se busca poner en discusión el carácter absoluto que se le asigna a estas conceptualizaciones, con el objeto de poder repensar los términos en los que se aborda la cuestión escolar en los años del primer peronismo.

El incremento anual que expresan los índices estadísticos respecto al número de matriculaciones experimentado por el sistema educativo en general, y por el nivel medio de la educación en particular, contribuyó a sostener que durante el primer peronismo se produjo un proceso de democratización del acceso al mundo escolar. Frente a esta aseveración, y entendiendo que el éxito de una política educativa de inclusión no puede ser medido basándose solo en la cantidad de alumnos matriculados anualmente, en este trabajo se modifica la perspectiva desde la que se analizan los datos existentes. Mientras que los estudios que versan sobre el tema hacen una lectura horizontal de la información, en la que exclusivamente se contemplan el total de inscripciones anuales, se destaca la necesidad de realizar una lectura diagonal de los datos que permita verificar cuántos de los ingresantes de cada cohorte abandonaron sus estudios a lo largo de este trayecto formativo.

La identificación de los niveles de desgranamiento que se visualizan, durante este período, entre los estudiantes que comenzaron a cursar el primer año del secundario y los que alcanzaron a proseguir sus estudios más allá del 
Ciclo Básico Bachiller, permiten observar que el índice de disminución real de la matricula fue de un $30,52 \%$. Es por ello que se identifica que el reconocimiento oficial de la terminalidad de este tramo formativo, que pasó a incluir el otorgamiento de un título nacional, evidenció una clara intención del gobierno por aumentar su injerencia en el control matricular de esta instancia educativa. Reconocimiento que, frente a la necesidad de regular la "producción" de docentes habilitados para dar clases en las escuelas primarias, también le permitió al Estado redireccionar el trayecto formativo de aquellos jóvenes que, por ser considerados no aptos para el ejercicio de la docencia, hubieran sido marginados del Ciclo Superior de las escuelas Normales.

Los años previos a 1950 también son señalados, por aquellos que estudian la política educativa peronista en clave de adoctrinamiento, como un período que se caracterizó por haber sentado las bases que posteriormente garantizaron el éxito de los mecanismos destinados a la generación de un consenso político. Consecuentemente, la democratización del acceso a la enseñanza y la búsqueda de una mayor centralización del sistema educativo, son identificadas como acciones que le permitieron al gobierno peronista alcanzar sus objetivos. Ahora bien, el consenso respecto a la caracterización de la política educativa en el período de aplicación del Segundo Plan Quinquenal no debe llevar a concluir apresuradamente que las prácticas escolares se redujeron, exclusivamente, a la intención de peronizar de los contenidos.

La visualización del derrotero del accionar reformista llevado a cabo por el peronismo, durante sus primeros años de gestión, permite dar cuenta de una intención por reelaborar los postulados propios de las prácticas escolares vigentes hasta el momento. Para el caso, dado que la matrícula de las distintas cohortes que iniciaban el secundario se desgranaba acorde los estudiantes avanzaban en sus trayectos formativos, para el gobierno resultó fundamental centrar estas reformas en el Ciclo Básico Bachiller. Frente a ello se buscó garantizar que, durante el tiempo en que los jóvenes permanecieran bajo el influjo del sistema educativo formal, se constituyeran en sujetos útiles para la Nación. Por otro lado la estructuración de distintos canales de participación con los que el gobierno instó a la colaboración de los docentes, en este proceso de reformas, permite matizar las ideas que refieren que, durante este período, los educadores acabaron siendo interpelados solo como ejecutores pasivos de las políticas educativas peronistas.

Buenos Aires, octubre de 2018 